Computing Professionals, Collective Organizing and Social Responsibility

\title{
Design Justice for the Missing Masses - A Sociotechnical Analysis to Resist Aarogya Setu
}

Pranav Menon, Tuisha Sircar

Published on: Oct 15, 2020

Updated on: Oct 13, 2020

License: Creative Commons Attribution 4.0 International License (CC-BY 4.0). 


\section{Design Justice for the Missing Masses - A Sociotechnical Analysis to Resist Aarogya Setu}

By Tuisha Sircar and Pranav Menon

tuishas@gmail.com

pranavmenon19@gmail.com

The COVID-19 pandemic has struck in a rapidly fast moving information age, where policy making reflects an incessant reliance on technology to address a crisis. Within epidemiology, contact tracing has become a standard method to control, monitor and track the virus and contain its spread. However, the growing determinism through which state and platform economy giants have aggressively mooted for digital contact tracing tools to remedy the infectious risk an individual may face from COVID 19, has been considered intrusive and privacy breaching (Deb, 2020).

It is imperative to assess whether the rule of law has been able to adapt to the growing modes of technocratic intervention pursued by the state, market and other stakeholders (Faulkner, 2012). Our emphasis is on whether India's Digital contact tracing tool, Aarogya Setu, is capable to withstand effective legal scrutiny for enabling grave violations to privacy of different individuals and community stakeholders? Whether it behaves not only as a privacy violating artefact without any no-harm safeguards but also as a privacy taking tool that modifies constantly through its actor-networks obfuscating or lapsing any legal challenge in court for such violations? Whether the state and market forces deploying the app during the pandemic exacerbates the existing structural inequalities for marginalised groups and essential workers? We intend to hypothesize that apps like Aarogya Setu, while enabling the 'performativity' of users as a necessity for a health duty, accessed through a smartphone, for security from COVID19, it denudes civil liberties of individuals and groups not only visa-vis the state but also other legal persons such as companies and associations.

In this position paper, we seek to adopt a socio-technical perspective for engendering design justice and collective organization for marginalised social groups; by giving a call to build equitable and ethical models or avoiding building 'inherently' political technologies. This proposal can be seen as a call to resist the highly intrusive model of deploying Aarogya Setu, by state and private sector, especially for those engaged in carrying out 'essential' services. We seek to adopt Bruno Latour's Actor Network theory (1992) to identify and comprehend the complex negotiations amidst actants, both human and non-human, and the networks enmeshed within such rapidly evolving artefacts.

Deploying the ANT allows us to interrogate the 'heterogeneity of the social' (1999) beyond the mere instrumental value of why a technology is enframed and deployed. On description of the Aarogya Setu 
app and its apparatuses, $\underline{1}$ we explore how the updates of the artefact behaves like a groom constantly shifting and delegating to the later versions of the code to identify and fix the technical and privacy concerns the app is confronted with. Thus, while the terms of use which the app relies upon functions as a law for the user, the in-built exceptions and amendments that the developers constantly evolve, repair and modify the requisite bugs and codes as norms within the app, thus obfuscating any reasonable legal challenge for an effective privacy safeguarding prescription.

We seek to argue that the call for downloading contact tracing apps like Aarogya Setu by state, private sector and neighbourhood communities negates the choice amongst users, especially those who are forced to give up their decisional autonomy. Much like an immutable mobile as Latour (1985) describes, the app enlarges the scale of representation for the user by giving him or her the illusion of security by identification of those contracting COVID19. The privacy policy constructed by the app has no concrete legislative backing and applies contrary to the bodily integrity, spatial as well as informational privacy, thereby violating the informed consent of users.

The technocratic apparatus of the app is designed in highly discriminatory terms as it fails to engender a holistic model of justice for persons and groups as rooted in the Puttaswamy decision. It fails to provide reasonable and proportional safeguards to privacy: a) by having no prescribed data limitation standard, b) opaqueness on open source claim on server side, c) with no liability or redressal mechanism, d) no safeguards on data usage. By disciplining the user to adopt self assessment tests, these apps emphasize on individual health securitization as a tradeoff for taking away any contestable claim for privacy as an individual or group, without any real assurance of less risk in contracting COVID19. This takes root in its imposition of biopower on the individual body that contains the virus inside of it to stay quarantined and eventually get its mobility back (Rowe, 2020). Such modes of control exerted by Aarogya Setu app is implicit in its design that is constantly updating and supervised through coders and developers working with the state.

The app is embedded with healthcare advice, AYUSH products promotion for enhancing immunity, public and private telemedicine options, policing quarantine compliance, media campaigns, COVID19 statistics, guidelines and safeguards. But these multiple nodes of actor-networks embodied in the app also relies on the user feeding their personal and health information which is identified through its use on compatible Operating Systems Bluetooth or GPS. The anonymization of information in context of all apps operating on Android, ioS and KaioS in India is quite poorly safeguarded as Arrka Study (2019) pointed out while documenting the data privacy breaches. Coupled with the artificial distinction of personal and non personal information pushed by the state to regulate the platform economy, the challenge to safeguard group privacy of marginalised workers, minorities and other civil society groups becomes of utmost urgency. 
The determinism rooted for deploying the app has only facilitated as a mirage without frequent testing and community health interventions in the state's COVID19 containment strategy. Rather the app is insidiously and obtusely collecting information to enhance the state's surveillance architecture as we see the nexus of techno-fascism in India. What makes Aarogya Setu even more insidious is in its ability to not merely magnify citizen state surveillance but also foster ground for newer forms of inter-se surveillance amongst citizens. By delegating its role to private citizens it fosters risk of abuse of power without effective regulation or data fiduciary liability norms.

Such delegation by the app to the tele-medicine companies (like Practo, 1mg, etc.), gig and platform economy giants (like Zomato, Amazon, Google, etc.), to use such information as 'resource' (Kovacs, 2020) that either track the 'bodies' of their workforce to assess productivity and employability (Kovacs, 2019) or using it to manipulate user preferences through on the web for selling their products (Zuboff, 2019). It also magnifies the voyeuristic tendencies of neighbourhood and para state groups like RWAs without safeguards of delegation putting privacy of tenants, househelps and sanitation workers at risk.

It is our endeavor to throw light upon strategies of resistance deployed by hackers, privacy activists and digital rights activists against the pervasive influence of app based contact tracing technologies in India. We believe it is imperative to contest the growing influence of such 'inherently' political surveillance technologies (Winner, 1980) using a socio-technical analysis to pinpoint the nodes of interaction and negotiations amidst actants and networks embedded within the artefact. Such an approach can help us foster tools of design justice for those actants that are either unaware of nuances of data protection or those who are forced to comply with the artefact due to fiat imposed by a higher authority.

Thus, it is imperative to engage in mass boycott campaigns of the app and mobilise amongst affected groups that are forced to download the app, especially when the state is providing access to services conditional to beneficiaries downloading the app. $\underline{2}$ It has become yet another armour for a neoliberal state to embed its politics of legibility and citizenship without addressing the data protection and anti surveillance safeguards. It is imperative we lay down certain thresholds wherein state and market agents are barred or have a responsibility against designing and deploying such privacy invasive technologies in the guise of health security. For privacy of health to remain a public good and justiciable right under Article 14, 19 and 21 of the Indian Constitution, there must be strict scrutiny and absolute liability against building such insidious technologies of control.

Mere hashtags of \#TechWontBuildIt is not enough from the platform economy sector developing these apps as effective compliance. There is a need to democratise public information by increasing access and literacy of digital tools as well as embedding ethical and justiciable elements through representation of marginalised groups while designing abolitionist tools within such technologies. 
It is hopeful that such methodology would engender notions of 'data justice' for users of app based contact tracing technologies from overt intrusiveness to collect such information, especially for those classified as 'essential workers' during the pandemic. Such an enquiry can allow various actors like ASHA and healthcare staff, sanitation workers, contract workers involved in the gig economy, etc., to collectively organise and resist the intrusion of such surveillance technologies that hamper their civil liberties and dignity. Such strategies can lay down the building blocks for recognizing decisional autonomy, privacy and open access of grassroot communities while encouraging them to adopt ethically humane and just technologies in the future.

\section{Author Bios}

Pranav Menon is a research scholar at the Centre for the Study of Law and Governance, Jawaharlal Nehru University.

Tuisha Sircar is an independent researcher and post-graduate in Sociology from South Asian University.

The Authors are grateful to Dr. Nupur Chowdhury, Assistant Professor, Centre for the Study of Law and Governance, Jawaharlal Nehru University, for her guidance and inputs.

\section{References}

Bhandari, V., Kak, A., Parsheera, S., \& Rahman, F. (2017). An Analysis of Puttaswamy: The Supreme Court's Privacy Verdict. IndraStra Global, 11, 1-5. https://nbn-resolving.org/urn:nbn:de:0168-ssoar54766-2.

Deb, S., 'Public Policy Imperatives for contact tracing in India' (April 11, 2020). IFF Working Paper No. 3/2020. Retrieved on September 10, 2020, from https://docs.google.com/document/d/1nDoPzygQyTetEguOlzula509y5f3f5YJDsA2Pd9906U/edit

Faulkner, A., Lange, B., \& Lawless, C. (2012). Introduction: Material Worlds: Intersections of Law, Science, Technology, and Society. Journal of Law and Society, 39(1), 1-19. Retrieved September 10, 2020, from http://www.jstor.org/stable/41350295

Internet Democracy Project (2020) Aarogya Setu Tracker Retrieved on October 7, 2020 from https://docs.google.com/spreadsheets/d/19pF6A2GXvbAjSefj_LHT9VC2Ct7h52SOiZsdsAwd5EM/edit\#g $\underline{\mathrm{id}=0}$

Loon, J. V. (2002). Risk and technological culture: Towards a sociology of virulence. New York: Routledge Justice K.S.Puttaswamy (Retired). vs Union of India And Ors., 2017 Writ Petition (Civil) No. 494 of 2012, (2017) 10 SCC 1 
Kovacs, Anja. (2019, May 28). When our bodies become data, where does that leave us? Retrieved September 30, 2020, from https://deepdives.in/when-our-bodies-become-data-where-does-thatleave-us-906674f6a969

Kovacs, Anja. (2020, August 6). Power to the People. Internet Democracy Project . Retrieved September 30, 2020, from https://www.youtube.com/watch? v=HV6auKTdBSw\&ab channel=MediaNama

Latour, B. (2008). Reassembling the social: An introduction to actor-network-theory. Oxford: Oxford University Press.

Latour, B. (1992). Where are the missing masses? The Sociology of a few mundane artefacts. In 969871780753105145 W. E. Bijker (Author), Shaping technology, building society: Studies in sociotechnical change. Cambridge, Mass. u.a.: MIT Press.

Winner, L. (1980). Do Artefacts Have Politics? Daedalus, 109(1), 121-136.

Zuboff, S. (2019). The age of surveillance capitalism: The fight for a human future at the new frontier of power. New York, NY: PublicAffairs

\section{Footnotes}

1. Latour (1999) has argued that technology primarily permits mediation in four ways: one, technology creates interference by creating new programmes of action and new possibilities; two, technology provides for new distributed practices, new compositions and new associations; third, technology folds time and space. What we think of as a black-boxed single thing is typically a complex of integrated parts whose composition is variable, sometimes stable and sometimes not; fourth, technologies delegate. They cross boundaries between symbols and things, and importantly they do the work that humans would otherwise have to do. ANT argues that nothing has meaning in itself. Things find significance only through their relations to other things and humans.

2. The Internet Democracy Project released an Aarogya Setu tracker that identifies the policy prescriptions for download ranging from categories - mandatory use of app, prescribed use for app, best efforts for app - amongst state departments, PSUs, private companies, district authorities, gig and transit services, healthcare employees, etc. $\Xi$ 